\title{
The effect of playing instrument on voice training ${ }^{1}$
}

\author{
Tuğçem Kar* \\ *Corresponding author, Assoc. Prof., Istanbul Technical University, Turkish Music State \\ Conservatory, Voice Training Department, İstanbul, Turkey, e-Mail:tkarqitu.edu.tr, ORCID: 0000- \\ 0002-0252-2537.
}

DOI 10.12975/rastmd.2021934 Submitted October 17, 2021 Accepted December 18, 2021

\section{Abstract}

The present study was conducted to determine the effects of playing an instrument on voice training. In the research; an experimental group of 8 people who played an instrument and did not receive voice training; a control group of 4 people who had no instrument training or voice training was formed. Within the scope of the pre-test, stroboscopic voice examination and voice analysis with CSL voice analysis program, voice physiology test and performance evaluation recording were applied to the members of both application groups. Then, the voice training program planned for six weeks was applied to both groups. All applications made for the pre-test were performed again for the post-test after the application in the same way. The hypothesis of the research is that the samples that have received instrument training can perceive voice training better and absorb music more easily compared to samples that have not received any instrument training until their undergraduate education begins. The research data were obtained by means of literature review, interview, questionnaire and application techniques and analyzed, interpreted and suggestions were made according to descriptive statistical methods. In the performance results of the research, both the first sample group and the second sample group increased their success after applying. The first sample group consisting of students who played an instrument was found to be more successful than the second sample group, which did not play an instrument. The analysis results for the 6 parameters selected in the MDVP voice analysis results were also graphed separately for the two groups. Videolaryngostroboscopic was applied to both sample groups as pre-test and post-test. The purpose of the method is to measure vocal cord health. Reflux was observed in 2 students in the first sample group and in 3 students in the second sample group. Each of these samples received a "better" rating from the three-person medical board, although no medical treatment was given. In the results of the voice physiology test, both sample groups were found to be more successful in the post-test compared to the pre-test.

\section{Keywords}

voice, instrument, breath, body awareness, training

1 This article was presented at 1st. International Rast Music Congress (IRMC), Turkey. 


\section{Introduction}

Individual voice training in Turkey starts at the age of 18 at the undergraduate level as "Full-time" for reasons such as completing the adolescence period and the development of the voice. The "Part-Time Choral Singing" departments of the conservatories accept students who are at least 16 years old. Since such departments provide part-time education, those who receive education - if they have not completed their high school education - must also continue their high school education. Students between the ages of 15 and 18 receive education in Fine Arts High Schools. In some of these institutions, there is only a "choir lesson", and in some, there is a collective lesson for the university entrance exam, which appears as an hour "voice training lesson" in the program in the last year. However, when researched, it will be seen that this course also does not include an education for its purpose, it does not provide an opportunity for individual education because it is a collective course, and people who are experts in the field of voice education do not give this course, and for these reasons, the content of the course is limited to choosing works for the university entrance exams. In addition, Children's Choirs consist of children aged 8-15, while youth choirs are sought for young people who have completed the second mutation period and have not reached the age of 26 .

As it can be understood from here, it is not possible to carry out individual voice training under the age of 18 in music high schools full-time in Turkey. Under these conditions, in front of a 15-year-old person who has completed eight years of primary education and wants to become an opera singer, to continue his music education by playing an auxiliary piano and a major instrument in Fine Arts High School, or to continue his music education by playing an auxiliary instrument piano and a major instrument until the last level of high school in conservatories. There are options such as continuing your education by playing. In addition to these, they have to wait until the age of 16 to apply to the "Part-Time Choral Singing Department" or to attend the Children's and Youth Choirs to receive vocal training at the undergraduate level at the university.

So, it is possible for the person who plans to study in Opera Department in Turkey to continue basic solfege, piano and instrument education or to take private individual voice training lessons until he reaches the age of 18 , that is, until his high school education is completed.

The problem of the research is to determine the effects of instrument education on voice education within the basic music education that the candidates who want to take opera education receive until their high school education is completed.

In the research;

Determining the positive or negative effects of instrument training on voice training; Paying attention to the fact that each of the students in the first application group have received and graduated from a different instrument at the high school level, but have not received any vocal training, first giving basic breathing, voice and phoniatric training, and then performing a 6-week voice training application and performing videoengostroboscopic sound examinations before this application. , taking sound recordings with the help of CSL 
sound analysis program and recording the performance with a piano accompaniment and pre-testing with the application of the sound physiology test; then posttesting with the same applications and reporting the change in their voices; (The results of the videolaryngostroboscopic sound examination were evaluated by a committee of 3 referees consisting of Prof. Dr. Kemal Değer and his clinical team -Dr. Şenol Çomoğlu, Speech Therapist Gayem Köprücü. Voice Physiology test results were evaluated by the researcher. The results of the CSL sound analysis program were evaluated statistically by the researcher in line with the selected parameters. Performance recordings with piano accompaniment were prepared by a jury of 3 referees, who expressed their valuable opinions in the proficiency evaluation form. Evaluated by Prof. Güzin Gurel, Assoc. Prof. Sebnem Unal, Assist. Prof. Çiçek Kurra Kanter.

Paying attention to the fact that the students in the second application group had not received instrument training or vocal training until that day, the same applications were made to this subject group and the change in their voices was reported with the evaluations of the same committees and the researcher with the pre-test post-test model;

Determining whether there are studies on respiratory awareness and bodily awareness, that is, breath and body awareness in instrument training, and the effects of physical ailments caused by playing an instrument on voice training, with the interview technique applied to instrument trainers;

After the applications were made, in order to support the research, the effects of instrument training on vocal training were applied to the students who started to receive vocal training at the undergraduate level after receiving instrument education at high school, and Turkish opera singers and voice educators who have achieved success in Turkey or abroad. It is aimed to be determined by the survey technique.

In line with these purposes, answers to the following questions are sought.

- Which muscles work when playing piano, violin, viola, cello, flute, guitar and bağlama instruments?

-What kind of problems does the incorrect use of the active muscles and skeletal system while playing these instruments cause, and how do these problems affect vocal training?

- Which instruments can be directly related to vocal training?

- How does breathing training on the instrument affect voice training? Do breathing techniques differ and how do they affect voice training?

- Is instrument training important in the intonation part of voice training?

- How do habits arising from playing an instrument affect voice training?

- If the students received bodily awareness and body awareness training during instrument training, what difference did this training make in vocal training?

- What effects did instrument trainings of successful Opera Artists and Voice 
Educators have on their voice training?

- What is the career development of students who have received or are receiving voice training in undergraduate after instrument education in high school, and what is the role of instrument training in this case?

It is thought that determining the effects of the instrument training taken until the undergraduate vocal education process is important in terms of preventing the negative effects and reinforcing the positive effects.

The research was conducted with the first sample group of 8 people who received instrument training at high school and did not receive voice training; With the second sample group of 4 people who did not receive instrument and voice training; with 10 educators for interviews with the educators of piano, violin, viola, cello, flute, bağlama and guitar instruments; with 1 trainer for body awareness training interview; with 10 artists and educators for the surveys to be applied to opera singers and voice educators; The questionnaires to be applied to students who have received instrument training in high school, have received or are taking voice training in undergraduate education are limited to 5 students.

The data collection tools (VLS sound examination machine, CSL voice recorder and MDVP analysis program, voice physiology test, performance evaluation form) to be used in the research are valid and reliable; that the instrument trainers and body awareness trainer who will participate in the interviews answered the questions in a way that reflects the truth; It is assumed that the students, voice educators and opera singers who will participate in the surveys have answered the questions in a way that reflects the truth.

The hypothesis of the research is that the samples who have received instrument training in fine arts high schools or conservatories can perceive vocal training better, absorb music more easily, have no difficulty in "ensemble" studies, breathe and breathe during instrument training, compared to samples that have never received instrument training until their undergraduate education begins. If they can apply their posture exercises correctly and naturally, it can also affect their voice training positively in terms of using the respiratory muscles, and for these reasons, playing an instrument can benefit voice training.

It should not be ignored that instrument training may have positive effects on voice training as well as negative effects. In this sense, if the samples that received instrument training before starting vocal training or started to receive instrument training at the same time, have physical ailments caused by playing instruments, the possible effects of these on vocal training and vocal organs will be determined by interviews with instrument trainers. The negative effects of playing an instrument without body awareness, wrong posture, wrong breathing and instrument training on vocal training are given as side effects.

Developed in 1904 by Frederick Metthias Alexander (1869 - 1955), the Alexander technique is a psycho-physical way of retraining. Alexander named neck, head and back awareness as primary control and focused his studies on the necessity of 
maintaining a comfortable and balanced posture without negative effects (Ergin, 2006). We can list the main elements of this technique as "blocking, directing or commanding and working on oneself". In the blocking phase; it is possible to gain the ability to control old habits and to give up the habit of reacting immediately without thinking (Gray, 1999: 41). Next comes the principle of "commanding and directing", which regulates the neck, head and back relationship. With the commands given to the student, such as "loosen the neck, head forward and up, extend and widen the back", attention is drawn to our awareness of the mistakes in our posture that we unconsciously make in our normal lives.

Mosche Feldenkrais focuses on the relations between development, learning and movement as practitioner, researcher, teacher and student" (Duruk, 2005). Feldenkrais has created his own technique by combining the western physiognomy, anatomy, neurology, system theory, the movement series used by infants in the development process, as well as the eastern philosophy of life and his experience in combat sports based on movement (Ergin, 2006). He determined the first stage as consciousness through movement and the second stage as functional integration lessons.

Kristin Linklater is an important educator working in the field of voice production for acting education, who connects body awareness and voice freedom with her work, which includes the approach of releasing the natural voice. In the Linklater technique, the channels in the voice emerge with emotions. Since each individual is different from each other, emotionally related vocal problems exist at different levels (Wygant, 2003: 10).

Hilde Langer - Ruhl founded the Department of "Examination and Training of Breath - Voice - Movement Education for Singers and Instrument Players" in Vienna in 1974. He gave respiratory and vocal training at the "Vienna Academy of Music and Performing Arts". Hilde Langer - Ruhl musicians are recognized as pioneers in the field of breath, voice and body studies.

"Lessac has studied how coordinating the body and brain can progress with attention and awareness. One must experience physical feeling at the same time as behavioral feeling. The training focuses on kinesthetic awareness, where the interpreter is expected to feel physically and to produce vocal sounds cognitively by changing habitual behaviors (Stemple et al., 2000: 433).

Laban movement analysis (LMA) sometimes referred to as Laban/Bartenieff movement analysis - is a method and language for describing, visualizing, interpreting and documenting human movement. Based on the original work of Rudolf Laban, developed and expanded by Lisa Ullmann, Irmgard Bartenieff, Warren Lamb, and others. LMA draws from many fields, including anatomy, kinesiology, and psychology (Newlove. 1993).

Diseases associated with instruments by Fry (1986), Norris (1993):

Violin and Viola: Neck pain, Thoracic Outlet Syndrome (Left arm) Carpal Tunnel Syndrome (Left arm), Cubital Tunnel Syndrome (Left arm), Flexor Carpi Ulnaris Tendinitis (Left arm), Rotator Cuff Tendinitis (Right arm), Extensor Carpi Radialis Tendinitis (on the right arm). 
Cello: Neck pain, Ulnar nerve compression, Flexor Carpi Ulnaris Tendinitis (Left arm), Rotator Cuff Tendinitis (Right arm), Extensor Carpi Radialis Tendinitis (Right arm).

Clarinet: Carpometacarpal joint injury (Right arm), Carpal Tunnel Syndrome, De Quervain's Syndrome, Lateral Epicondylitis (Right and left arm).

Oboe: Extensor Carpi Radialis Tendinitis (Right arm), Lateral Epicondylitis (Right and left arm), Ulnar nerve compression, De Quervain's Syndrome, Neck and back pain.

Trombone: Lateral Epicondylitis (on the right arm).

Horn: Extensor Carpi Radialis injury (Right arm), Injury to the posterior ligament of the wrist (Right arm).

Percussion Instruments: Medial Epicondylitis, Extensor Carpi Radialis Tendinitis, Carpal Tunnel Syndrome, De Quervain's Syndrome.

Guitar: Triceps Tendinitis (Right arm), Focal Dystonia of index, thumb and middle finger (Right hand), Thoracic Outlet Syndrome (Left arm), Carpal Tunnel Syndrome (Left arm), Flexor Carpi Ulnaris Tendinitis (Left arm).

Harp: Neck pains, Flexor and Extensor tenosnovit in the Thumbs, Extensor Carpi Radialis Tendinitis, Medial Epicondylit.

Saxophone: Back and neck pain, Extensor Carpi Radialis Tendinitis (Right and left arm).
Bassoon: De Quervain's Syndrome, Back and neck pain.

Flute: Ulnar nerve compression (Left arm), Extensor Carpi Radialis Tendinitis (Left arm), Thoracic Outlet Syndrome (Left and right arm), Back and neck pain, De Quervain's Syndrome (Right and left arm), Focal in ring finger and little finger Dystonia (Left arm).

Keyed Instruments; Piano, Accordion: Thoracic Outlet Syndrome, Medial Epicondylitis, Lateral Epicondylitis, Tendinitis of the Flexors and Extensors of the Wrist, Carpal Tunnel Syndrome, De Quervain's Syndrome, Nervous knots on the back of the wrist, Focal Dystonia in the entire hand, thumb, and other fingers (Chong et al., 1989).

\section{Method}

This research is carried out to measure the effect of playing an instrument on vocal education. For this purpose, survey and interview techniques as descriptive techniques in the research; As a trial model, the application technique was determined as the research method.

Trial models are research models in which data to be observed are produced directly under the control of the researcher in order to try to determine cause-effect relationships. While the existing situation is observed with screening models, in the trial model, what is desired to be observed is produced by the researcher (Karasar, p: 87, 2005).

Interview and questionnaire forms prepared as data collection tools; videosengostroboscopic sound examination, CSL recorder MDVP sound analysis program; voice physiology test 
and performance evaluations were applied to the sample group.

In the research; As the first practice group, a group of 8 subjects who graduated from Fine Arts High Schools or Conservatories by playing different instruments and did not receive individual vocal training was formed; As the second application group, a subject group of 4 people who had no instrument training and individual voice training was formed.

As the first stage, stroboscopic sound examination and sound analysis with the CSL sound analysis program were applied to the members of both practice groups within the scope of the pre-test, and the current state of their voices was determined. In the second stage within the scope of the pre-test, the voice physiology test was applied to both groups and their voice anatomy information was measured. In the last phase of the pre-test, it was ensured that the subjects performed a Turkish piece with piano accompaniment, and this performance was recorded and prepared for the evaluation of a 3-person jury. Then, the practices were started and the voice training program planned for six weeks was applied to both groups. All applications for the pre-test were performed again for the post-test after 6 weeks of application in the same way.

Voice examinations and voice analysis data were provided by the Head of the Department of Otorhinolaryngology, Çapa Medical Faculty, Prof. Dr. It was evaluated by Mr. Kemal Değer and his team. Performance recordings were made by Istanbul University State Conservatory Voice educator Prof. It was evaluated by Ms. Şebnem Ünal and the members of the jury. Voice physiology test was evaluated by the researcher.

In order to support the research, the importance of respiratory awareness and bodily awareness in instrument training, and physical ailments caused by playing an instrument were determined by interview with instrument trainers. After receiving instrument training at high school, students who started to receive voice training at the undergraduate level; The effect of instrument training of Turkish opera singers and voice trainers, who have achieved success in Turkey or abroad, on voice training has been measured with the survey technique.

Interviews and questionnaires were applied by the researcher in the institutions where the students were educated and the educators and artists were working. During the applications, it was given importance that the samples were comfortable in terms of time. Again, it was observed that the places and conditions of the samples were positive. Data collection tools have been prepared in a way that is easily understood by the source person and is impartial. Factual questions were also included in the data collection tools. The questions from which we will obtain these data are openended questions. In addition to factual questions, fixed questions were included in the surveys. In closed-ended questions, three answer alternatives were presented to the source person. The research was carried out over a period of 8 months.

Samples of the first application group are 1st year students of Marmara University Atatürk Education Faculty Music Teaching Department. All of the applications were applied by the researcher for 6 weeks during the lessons on the same day and 
at the same time every week in the Individual Voice Training class where the researcher was training. Pre-test and post-test performance recordings were also made with the acoustic piano in this class. The piano accompaniment of the works sung in the recordings was played by the researcher. The applied voice physiology test was also applied in the same class, paying attention to the comfort of the samples in terms of time and mind. The samples of this application group were selected from the graduates of music high schools (GSL, IÜDK, MSGSÜ).

Samples of the second application group are Nazım Academy - Voice Education 1st year students. The applications were applied by the researcher for 6 weeks in this educational institution. Since the samples in this group work in various occupations, the working days and hours vary. Pre-test and post-test performance recordings were made in the same institution and on digital pianos of the same brand. The piano accompaniment of the works sung in the recordings was played by the researcher. The applied sound physiology test was also applied in the same places, paying attention to the comfort of the samples in terms of time and mind. The samples of this application group were selected from general high school (Vocational High School, Teacher High School, Anatolian High School, Flat High School) graduates.

In the study, Voice Examination and Voice Analysis were applied by the speech therapist with the help of an otolaryngologist before and after the application in Istanbul University Capa Medical Faculty - Ear Nose and Throat Polyclinics. The evaluations were made by the members of the 3-person committee consisting of the Head of the Department of Otorhinolaryngology, professor, ENT doctor and speech therapist.

Evaluation of the performance recordings in the research was made by the members of the 3-person committee consisting of Istanbul University State Conservatory Voice Educator, 1 professor, an associate professor and an assistant professor.

The researcher carried out the implementation of the interviews and questionnaires in the research, and the interviews and questionnaires were applied to the artists working in the institutions where the students received education, where the educators and artists were working, and to the artists working abroad. During the applications, it was given importance that the samples were comfortable in terms of time, place and mind.

\section{Findings and Conclusions}

\section{Videolaryngostroboscopic Results}

0 : same, +1: better, -1: worse. The definition of "better" is used for better union of the vocal fold and reduction of edema. Reflux was observed in some of the samples. Apart from this, no lesion was found. It is in question that education and reflux are taken under control and hygiene becomes better in the samples where progress is made even though medical treatment is not used. Normally, the muscles between the stomach and the esophagus do not allow the acid secretion to escape upwards. However, in some diseases, this escape can be. If this acid leak reaches the esophagus, it is called gastroesophageal reflux (GER), and if it reaches the throat, it is called 
laryngopharyngeal reflux (LFR). These can be counted as: loosening of the epiglottis valve between the stomach and the esophagus, gastric hernia, obesity, excess acid secretion from the stomach, slowing the passage of food from the stomach to the intestines, smoking and alcohol use, eating high-fat foods, sending excess food to the stomach at once, lying on the back. Factors such as reflux facilitate the formation.

Table 1. VLS Exam Results

\begin{tabular}{|c|c|c|c|}
\hline First Sample Group & $\begin{array}{l}\text { BETTER } \\
\quad+1\end{array}$ & $\begin{array}{l}\text { SAME } \\
0\end{array}$ & $\begin{array}{c}\text { WORSE } \\
-1\end{array}$ \\
\hline M. Gökçen & & $\mathrm{X}$ & \\
\hline O. M. Ezber & $\mathrm{x}$ & & \\
\hline Y. Kul & & $\mathrm{X}$ & \\
\hline B. Ağılkaya & $\mathrm{x}$ & & \\
\hline B. Özkan & $\mathrm{x}$ & & \\
\hline Z. Ü. Ardil & & $\mathrm{X}$ & \\
\hline T. Karslıoğlu & $\mathrm{x}$ & & \\
\hline S. Polat & $\mathrm{x}$ & & \\
\hline $\begin{array}{l}\text { Second Sample } \\
\text { Group }\end{array}$ & $\begin{array}{l}\text { BETTER } \\
+1\end{array}$ & $\begin{array}{c}\text { SAME } \\
0\end{array}$ & $\begin{array}{c}\text { WORSE } \\
-1\end{array}$ \\
\hline D. Krokhalev & & $\mathrm{X}$ & \\
\hline A. Boyacıoğlu & $\mathrm{x}$ & & \\
\hline P. Dursun & $\mathrm{x}$ & & \\
\hline Ö. Çuhadar & $\mathrm{X}$ & & \\
\hline
\end{tabular}

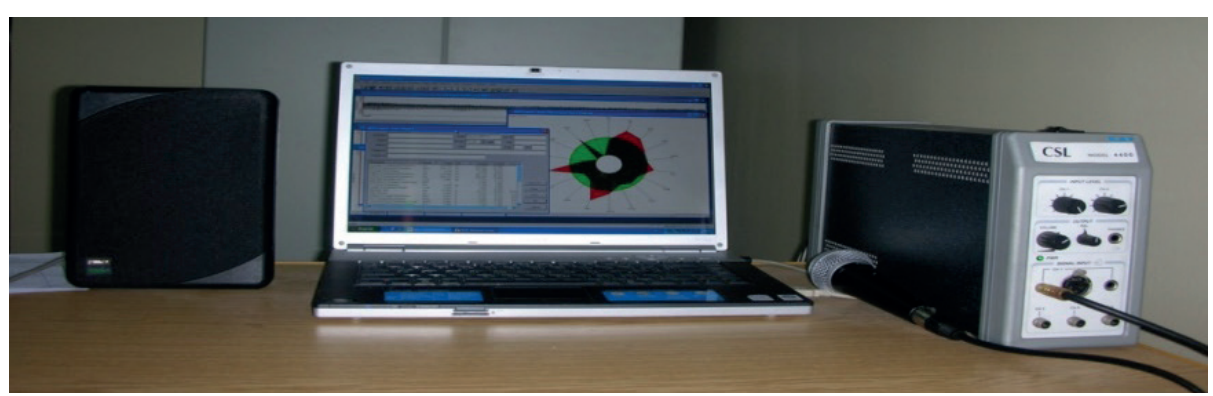

Picture 1. MDVP Acoustic Voice Analysis Program and CSL Voice Recording System 


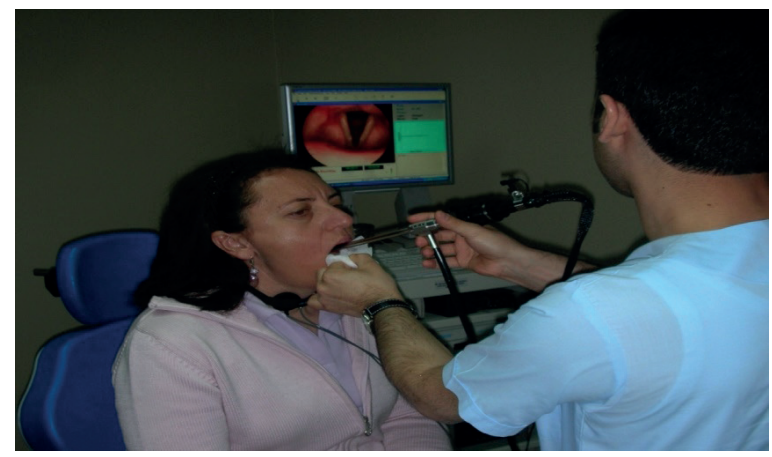

Picture 2. VLS Medical Inspection

MDVP Acoustic Voice Analysis Program and CSL Voice Recording System Findings and Conclusions

Fundamental Frequency (Fo): It is the frequency of the primitive sound that occurs at the level of the larynx. It is expressed in Hertz $(\mathrm{Hz})$. It is the number of glottic cycles that occur in one second. The duration of each cycle is called a period and is expressed in milliseconds. A change in the fundamental frequency is a change in the velocity of the glottic cycle. The most effective method for this is to change the mechanical properties of the vocal cord. As the vocal cord length increases, the area exposed to subglottic pressure will expand and the opening phase of the glottic cycle will shorten. Since the stretched elastic structures will come to the midline more quickly, the closure phase will also shorten and Fo will increase. In addition, Fo can be increased by contraction of the cricothyroid muscle. While Fo is $100-150 \mathrm{~Hz}$ on average in men, it is between $150-250 \mathrm{~Hz}$ in women. Fo increases especially in neurological motor deficits. The simplest sound produced can be expressed as a sinusoidal wave of a certain amplitude with a frequency Fo. Sounds in nature are found in complex form. Any complex, periodic sound can be broken down into frequency components with the help of "Fourier analysis".
Fourier theory was formulated by 19th century French physicist Joseph Fourier. According to this theory, any periodic complex waveform; It consists of a series of simple sinusoidal waves with different frequencies, amplitudes and phases. In other words, complex sounds consist of parts called partials. If the partials are whole multiples of Fo, the resulting sounds are called harmonics. If they are not completely solid, the resulting sound is called noise. Noise is caused by incomplete closure or irregular vibration of the vocal folds.

First Sample Group - Pre-Test: The arithmetic mean of the Basic Frequency values of the 4-person female sample group is $239.486 \mathrm{~Hz}$, which corresponds to the $150-250 \mathrm{~Hz}$ values within the standard value range for women. When the fundamental frequency values of the male sample group were examined, values were found in the middle and within the range of the standard value range of 100 - $150 \mathrm{~Hz}$. In addition, when the standard deviation values of the male and female sample groups were examined separately, a standard deviation of 9.14 was found in the male group, while a standard deviation of 37.56 was found in the female group. It can be concluded that the male sample group gave results more parallel to the 
mean standard values, and the female sample group showed a greater deviation from the standard values, based on two extreme results other than the standard data, as mentioned above.

First Sample Group - Post-Test: The arithmetic mean of the Baseline Frequency values of the 4-person female sample group is $244.230 \mathrm{~Hz}$, which corresponds to the upper limit of the 150 $250 \mathrm{~Hz}$ values within the standard value range for women. When the fundamental frequency values of the male sample group were examined, values were found in the middle of the standard value range of $100-150 \mathrm{~Hz}$ and within the range. In addition, when the standard deviation values of the male and female sample groups were examined separately, a standard deviation of 7.56 was found in the male group, while a standard deviation of 26.30 was found in the female group. It can be concluded that the male sample group gave results more parallel to the mean standard values, and the female sample group showed a greater deviation from the standard values, based on two extreme results other than the standard data, as mentioned above. After the voice training, the data of both groups approached the mean values compared to the values before the voice training. Education in women was more effective than men in approaching the mean values.

Second Sample Group - Pre-Test: PreTest: The arithmetic mean of the Basic Frequency values of the 3-person female sample group was $243,877 \mathrm{~Hz}$, and it approached the upper limit of 150-250 $\mathrm{Hz}$ values within the standard value range for women. When the fundamental frequency value of the male sample was examined, values were found below the standard value range of $100-150 \mathrm{~Hz}$ and within the range. Since the male sample is one person, the standard deviation value cannot be calculated. In the female group, a standard deviation value of 13.10479551 was found.

Second Sample Group - Post Test: The arithmetic mean of the Basic Frequency values of the 3-person female sample group was $226,801 \mathrm{~Hz}$, which corresponds to the $150-250 \mathrm{~Hz}$ values within the standard value range for women, but decreased compared to the 6-week pretreatment period. When the female sample group is examined individually, it is seen that the values show a decrease. A standard deviation of $3.55729518 \mathrm{~Hz}$ is observed in the female sample group. The basic frequency value of the male sample increased to $107.363 \mathrm{~Hz}$ after 6 weeks of voice training and entered the 100-150 $\mathrm{Hz}$ range, which is the standard value range for men. Since the male sample is one person, the standard deviation value cannot be calculated. In the female sample group, a sample with a value of 226,801 $\mathrm{Hz}$ is the sample closest to the lower limit of the standard value range. One sample, on the other hand, was the sample closest to the upper limit of the standard value ranges, with a value of $233.124 \mathrm{~Hz}$.

Maximum Phonation Time (MPT): It is an easy and very useful method to measure. After taking a deep breath, the patient is asked to make the sound "a" for as long as he can. The "maximum phonation time (MPT)' is determined with the help of a stopwatch. While the MPT is lengthened in adductor spasmodic dysphonias with severe glottic closure, it shortens in cases of glottic insufficiency, submaximal effort, and pulmonary insufficiency. 
First Sample Group - Pre-Test / PostTest: MPT parameter corresponds to Maximum Phonation Time measurement. Normal values are 16-25 seconds for women and 22-34 seconds for men. These figures are expected to be prolonged in adductor spasmotic dysphonia if glottic closure is severe, and shortened in glottic insufficiency submax effort and pulmonary insufficiency. Except for one sample in women, this parameter is seen below the mean values. In males, data are found well below the average values. Only one sample in the sample group gave a value close to the lower limit of the mean values before the training. After the training, the two samples doubled their pre-training parameters and approached the lower limit of the normal values. However, although it was generally lower in the male sample group, these periods were also below the normal values in females. Therefore, it can be mentioned that the maximum phonation time is shortened with glottic insufficiency, submax effort and pulmonary insufficiency. While men after training increased this period by 3.6 seconds on average compared to pretraining, women did not show any change in lengthening or shortening their pretraining time. As a result of the training, the women remained close to the lower limits of the normal values, while the men improved their very low time after the training, but they still could not get close enough to the lower limits of the normal values.

Second Sample Group - Pre-Test and Post-Test: MPT parameter corresponds to Maximum Phonation Time measurement. Normal values are 16-25 seconds for women and 22-34 seconds for men. These figures are expected to be prolonged in adductor spasmotic dysphonia if glottic closure is severe, and shortened in glottic insufficiency submax effort and pulmonary insufficiency. A standard deviation of 6.297883242 is observed in the female sample group. After six weeks of voice training, the values of the remaining ones, except for one of the samples, increased by 1-2 units. It can be mentioned that glottic insufficiency, submax effort, and pulmonary insufficiency shorten the maximum phonation time. The standard deviation of the female sample group after the training was 5,316327053. The single male sample remained below the standard values after the training. A sample is even 6.5 units behind the lower limit of the standard values. The other 3 female samples also regressed and remained at the lower limit of the standard values.

S/Z Ratio: It means the ratio of the maximum consonant duration s that can be extracted in one breath to the duration of the $z$ consonant. The $S / Z$ ratio is useful in measuring the adequacy of the laryngeal valve. Its normal value is 1-1.4. In cases where vocal cord vibration is impaired or glottic closure is not complete, it is expected that the $\mathrm{Z}$ duration will be shortened and therefore the $S / Z$ ratio will increase. It is used to evaluate the results of the applied treatment. The utility of this method is mostly limited to screening patients with vocal cord nodules.

First Sample Group - Pre-Test and PostTest: A high rate can be considered as an indicator of cases where vocal cord vibration is impaired or glottic closure is not complete. The benefit of the method is that it is used in the screening of patients with cord nodules. When the values before and after education are observed in the male and female sample, they show an 
increasing trend without exception. The increasing trend varies between $0.6 \%$ and $66 \%$. When the standard deviation of the mean is examined before and after the training, a two-fold increase is observed. It can be said that the standard deviations have increased by two times.

Second Sample Group - Pre-Test and PostTest: A high rate can be considered as an indicator of cases where vocal cord vibration is impaired or glottic closure is not complete. The benefit of the method is that it is used in the screening of patients with cord nodules. A male sample and a female sample could not reach the lower limit of the standard values before and after the training. Another female sample remained within the standard values in the pre- and post-test, while the last female sample exceeded the upper limit of the standard values. Means generally increased in the posttest, with no significant increase in standard deviations.

Harmonic / Noise Ratio (HNR): In a complex sound, whole multiples of the fundamental frequency form harmonics. If its frequency is not an exact multiple of Fo, it is considered noise. The noise component is caused by turbulent airflow due to incomplete closure of the glottis during the vibratory cycle or irregular vibration of the glottis. The increase in airflow at the level of the glottis causes turbulence. The loss of harmonic components at high frequencies is due to the short or incomplete closure phase during vibratory cycles. The ratio of the sound energy, the frequency of which is Fo and its harmonics, to the sound energy at the noise frequencies is called the Harmonic / Noise ratio. Harmonic / Noise ratio correlates with dysphonia.
First Sample Group - Pre-Test and PostTest: Integer multiples of fundamental frequency Fo are harmonic. If it is not full floor, it is said that there is noise. Harmonic/Noise Ratio correlates with Dysphonia. Since the only parameter that will indicate Dysphonia in our data is Maximum Phonation Time and the longer this period indicates Dysphonia, the correlation results between Maximum Phonation Time and Harmonic/Noise ratio data can be examined.

Second Sample Group - Pre-Test and PostTest: Integer multiples of fundamental frequency Fo are harmonic. If it is not full floor, it is said that there is noise. Harmonic/Noise Ratio correlates with Dysphonia. Since the only parameter to indicate Dysphonia in our data is Maximum Phonation Time, and the longer this period indicates Dysphonia, the correlation results between Maximum Phonation Time and Harmonic/Noise Ratio data can be looked at.

Intensity: The unit of intensity is expressed in decibels. Average intensity during normal speech is about 75-80 dB in modal voice. Violence is slightly higher in men than in women. Loud sounds have increased intensity. Because increased laryngeal tone increases the intensity by causing increased glottic resistance. Changes in intensity are brought about by adjustments in muscle activity, pressures, and airflow. For example, sound intensity increases with increases in subglottic pressure. The closure time and degree of closure of the vocal cords is the control mechanism in this situation. Higher vocal fold resistance requires higher subglottic pressure, which results in an increase in loudness. At low frequencies, vocal fold resistance is the major factor in controlling 
loudness, while at high frequencies airflow becomes the dominant variable.

Jitter: It refers to the variation in each period. It is expressed in milliseconds or as a percentage of the glottic cycle.

Shimmer: It refers to the amplitude variation in each glottic cycle. It is expressed as a percentage or decibel. It expresses the amplitude changes in the sound wave at short intervals.

Considering the first group and second group determining parameters, statistical data were analyzed with changes according to before and after the voice training application. In the statistical analyses, the normal changes of the parameters compared to men and women were taken into account. Because, the normal value ranges of men and women differ in some parameters. Therefore, the male and female groups were not considered as a single sample group at this point. Otherwise, false indications may occur.

Beyond that, while performing statistical analysis; mean values were calculated, standard deviations of the mean values in all samples were calculated, compared with the maximum and minimum extreme values in the sample and interpreted according to their relative relationships. Again, these analyzes were extended when necessary to separate all statistical parameters as male and female.

The medical and scientific changes of the parameters and the physiological problems that these changes can cause are explained. Significant parameters were selected from the analyzes and these were examined. In this sense, while the medical and physiological disorders and changes are detected in the first stage, these analyzes are expected to shed light on the second stage, which will include the examination of the effect of instrument training on voice training. Before and after the voice training, the data were analyzed both numerically and qualitatively. Among the parameters for the analysis, Fo: Fundamental Frequency, MPT: Maximum Phonation Time, S/Z RATIO, NHR: Harmonic/Noise Ratio, JITA: Jitter, ShdB: Shimmer were found significant and evaluated before and after the training.

What kind of medical and physiological changes these parameters are in the analysis, their units and theoretical definitions are given. In some cases, apart from evaluating the parameters individually, it is also meaningful to compare them with each other. For example, prolonged maximum phonation time indicates dysphonia. Harmonic noise ratio is correlated with dysphonia. In this case, the correlation between NHR and MPT can be analyzed. If the correlation calculation between two data sets gives a value close to 1 , it can be said that the two data sets are correlated. On the other hand, data close to 0 can be obtained. In this case, the two data can be said to be uncorrelated.

\section{Performance Records Findings and Results}

The jury, consisting of a committee of three, made performance evaluations separately. They were shown the videorecorded performances of the members of the first application group and the second application group in the pre-test and post-test and were asked to make an assessment among five ratings: "not enough, a little adequate, sufficient, quite sufficient, very sufficient". Each of 
the six selected parameters was evaluated out of 100 points and determined as 20 points not sufficient, 40 points slightly sufficient, 60 points sufficient, 80 points quite sufficient, and 100 points very sufficient. Pre-test, post-test and total averages of each group were taken.

Both the first sample group and the second sample group increased their success after applying it. A significant difference was found in the first sample group who played an instrument. The first sample group consisting of any instruments. students who play an instrument was found to be more successful than the second sample group who did not play an instrument.

In the first sample group playing an instrument, the performance averages of the 3 samples playing the string instruments were compared to the performance averages of the samples playing the other instruments; The performance averages of the samples that played other instruments were also higher than the performance averages of the samples that did not play

Table 2. Performance Records Results

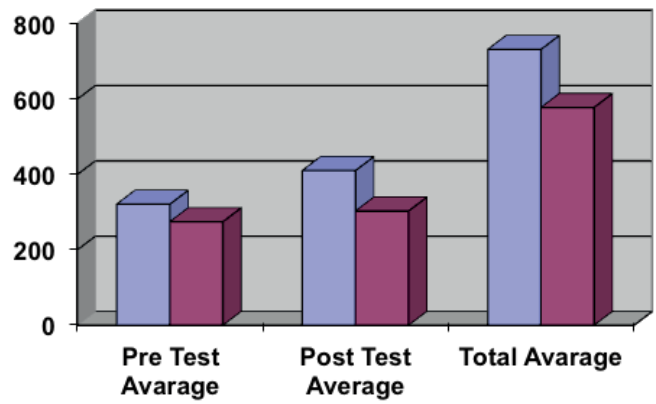

Voice Physiology Test Findings and Results

Voice Physiology test was applied to both sample groups before and after 6 weeks of voice training. Both sample groups were successful in the posttest compared to the pretest. The first sample group increased from $41,875 \%$ success average to $89,375 \%$ success average, the second sample group increased from $41.25 \%$ success average to $92.5 \%$ success average. When the post-test achievement developments of the two sample groups are examined, it is seen that the second sample group is $3,125 \%$ more successful.

Table 3. Voice Physiology Test Results

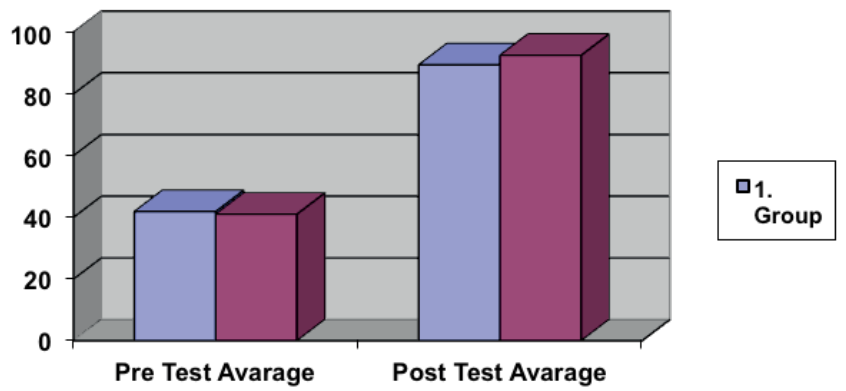




\section{Survey Findings and Results}

In the questionnaires applied to the opera students, it was seen that $20 \%$ of the samples were trained on bodily awareness and $80 \%$ on respiratory awareness. $80 \%$ of the samples think that the respiratory awareness and bodily awareness training they received during instrument training contributed to voice training. $100 \%$ of the samples stated that the natural posture they learned during their instrument training provided comfort during their vocal training, the basic music knowledge they learned formed a basis during their vocal training, the solfeggio and harmony training they received made it easier to learn the works during their vocal training, and the musical terms they learned during their vocal training. They agreed that the chamber music and orchestral works they performed were beneficial in their "ensemble" studies during their vocal training. $60 \%$ of the samples agreed that the symphonic work and opera composers they knew during their instrument training and the music history education they received were beneficial for them to assimilate the music periods during their vocal training. $80 \%$ of the samples agreed that the musicality studies they had done during their instrument training improved their musicality during their vocal training. $40 \%$ of the samples agreed that learning to use the diaphragm during instrument training had a positive effect on vocal training. $20 \%$ of the samples agree that the wrong habits acquired during instrument training have a negative impact on vocal training, that posture, sitting, holding the instrument and blowing techniques, which constitute the technical dimension of instrument training, have a negative effect on vocal training, and that the technical training in the instrument coincides with the vocal training technique.
In the surveys applied to opera educators and artists, it was seen that $40 \%$ of the samples were trained on bodily awareness and $20 \%$ on respiratory awareness. $60 \%$ of the samples think that the respiratory awareness and bodily awareness training they received during instrument training contributed to voice training. $70 \%$ of the samples agreed that the natural posture they learned during instrument training provided comfort during vocal training. $90 \%$ of the samples learned that the basic music knowledge they learned during their instrument training formed a basis during their vocal training, the musical terms they learned were useful during their vocal training, the chamber music and orchestra works they performed were beneficial in their "ensemble" studies during their vocal training, the symphonic work and opera they had known. They agreed that the composers and the music history education they received were beneficial for them to assimilate the musical periods during their vocal training, the musical terms they learned were beneficial during their vocal training, and the musicality studies they had done improved their musicality during their vocal training. $100 \%$ of the samples agree with the idea that the solfeggio and harmony training they have received enables them to learn the works more easily during their vocal training. $30 \%$ of the samples agreed that learning to use the diaphragm during instrument training had a positive effect on vocal training. $20 \%$ of the samples agree that the wrong habits acquired during instrument training have a negative impact on vocal training, that posture, sitting, holding the instrument and blowing techniques, which constitute the technical dimension of instrument training, have a negative effect on vocal training, and that the technical training 
in the instrument coincides with the vocal training technique.

The researcher thinks that it is important to comprehend and feel all the fundamentals of music, and in this sense, playing an instrument and singing should be seen as a tool and making music as a goal. He thinks that if the vocal health and capacity of those who play his instrument with the right posture and technique allow, his singing will be positively affected. She thinks that her own instrument playing experience helps her singing in ensemble works, learning pieces, singing legato, and improving her understanding of nuance and musicality.

Instrument educators, in line with their experience, are united in the opinion that playing an instrument has no negative effect on singing, on the contrary, singing develops instrumentalism and instrumentalism develops singing. However, they stated that the body posture of an instrumentalist with the wrong technique may not be natural, so he may experience physical discomfort and these discomforts and tensions may negatively affect his singing. They shared that the singers who play instruments can absorb their musical knowledge, solfeggio and harmony training, the fundamentals of music and polyphony more easily than others. While conveying these views, they also cited the example of a pianist who has no problems with his technique, getting injured because he breathes incorrectly while playing the piano, and that playing an instrument by an instrumentalist who already has a lesion in his voice may cause more dysphonia in his voice.

The results of the study showed that the samples playing the violin, viola and cello were more successful in vocal education compared to the samples playing other instruments and samples not playing instruments. The cello was seen as an instrument more suitable for human anatomy than the violin and viola. The flute was found to be more suitable for sound among woodwind instruments and than copper wind instruments in terms of having the least tension on the lips. It has been stated by the expert that the flute breathing technique does not have an understanding that prevents voice training. It has emerged that the guitar can have a positive effect on singing in terms of sensing the resonance, since it is in direct contact with the rib cage. Piano was found suitable for pre-vocal training in terms of assimilation of polyphony. In our study, there were no significant differences between the success of the sample group that played an instrument and the sample group that did not play an instrument. It is thought that this significant difference can be reached by choosing the first sample group among the samples that play the instrument better and given bodily awareness training, and the second sample group is selected from among the samples that do not have lesions in their voices.

\section{Recommendation}

The sample is exemplary; the research is healthier for therapeutic purposes.

For both sample groups, it is recommended to select samples with no lesions in their voices, with the thought that it will make the research more meaningful.

It is recommended that VLS examinations be carried out at the end of all application weeks by improving financial 
opportunities, with the thought that the results of the research may be more decisive.

It is recommended to further expand the content of the application on voice training, respiratory awareness and bodily awareness.

\section{Limitation of Study}

Sample groups are limited to 12 people.

Application is limited to 6 weeks.

VLS applications are limited to 2 times as pre-test and post-test.

\section{Acknowledgement}

I would like to thank the students of the sample groups, the performance evaluation jury, the VLS evaluation jury, and everyone who answered the questionnaire. 


\section{Biodata of Author}

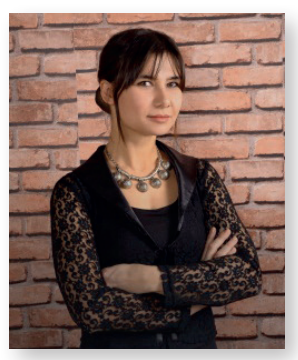

\section{Tuğçem Kar}

Assoc. Prof. Tuğçem Kar, PhD She was born in Tekirdağ in 1984. She studied piano and violin at Istanbul Avni Akyol Anatolian Fine Arts High School between 1998-2002. Between 2000-2004, she worked in Istanbul University State Conservatory - Opera / Choral Singing Department with Prof. Şebnem Ünal. In 2002, she started studying piano and viola at Marmara University Atatürk Faculty of Education - Department of Music Teaching, and graduated in 2006 with the first degree. In 2002, she played the role of "Nihal" in the opera "Așk- ו Memnu" composed by Selman Ada and directed by Çetin İpekkaya; In 2003, she played the role of "The Boy" in the opera "Kuva-i Milliye" composed by Orhan Șalliel and directed by Murat Göksu. She completed her first master's degree in Marmara University Institute of Educational Sciences in 2008 and she completed her second master's thesis at Istanbul University State Conservatory Institute of Social Sciences in 2012. Between 2007 and 2018, she taught Voice Training at Marmara University as a contracted lecturer. In December 2019, she started to work as a lecturer in ITU-TMDK Voice Education Department. She completed her doctorate at Marmara University Institute of Educational Sciences in January 2020. She was awarded the title of Associate Professor in Performing Arts on March 10, 2021. 


\section{References}

Duruk, Ș. (2005). Feldenkrais methodu, http://www.sirinduruk.com/ Web adresi.

Fry, H.J.H. (1986). Overuse syndrome in musicians: Prevention and management. The Lancet september (728-731).

Ergin, E (2006). Gitar Eğitiminde Karșılașılan Önkol Hastalıklarına İlișkin Öğrenci Görüșleri”, Yüksel Lisans Tezi, Gazi Üniversitesi Eğitim Bilimleri Enstitüsü.

Gray, J: (1999). Alexander Tekniği Rehberiniz, (0. Erkoldas, Çev.), İmge kitabevi (Eserin aslının basım tarihi 1990), Ankara.

Newlove, J. (1993) Laban for Actors and Dancers: Putting Laban's Movement Theory into Practice, Nick Hern Books. ISBN 9781-85459-160-9

Karasar, N. (2005). Bilimsel Araștırma Yöntemi, Nobel Yayıncılık, 15. Basım, Ankara.

Stemple, J. C., Glaze, L. and Gerdemann, B. K. (2000). Clinical Voice Pathology Theory and Management (Third Edition), Singular Publishing Group, San Diego.

Wygant, D. L. (2003). Coordinating Skinner Speech and Linklater Voice For The Beginning Actor, Master of Arts, A Thesis in Theatre, Graduate Faculty of Texas Tech University. 